Riesgo de convulsiones por uso de vacunas de células enteras contra la tos ferina, o contra el sarampión, la parotiditis y la rubéola

En los años treinta se detectó por vez primera una relación entre la vacunación contra la tos ferina y ciertos efectos neurológicos adversos. En la misma época, varios estudios mostraron una asociación entre la administración de la vacuna triple (toxoides tetánico y diftérico y células enteras contra la tos ferina, DTP) y un mayor riesgo de sufrir convulsiones febriles y encefalopatía. Los posibles efectos de la vacuna triple contra el sarampión, la parotiditis y la rubeóla (MMR) han sido menos estudiados. En 1991, Griffin et al. notificaron una asociación entre la administración de la MMR y un mayor riesgo de convulsiones febriles durante los primeros 7 a 14 días después de la vacunación, y en 1995 Farrington et al. descubrieron que este riesgo existía durante los primeros 6 a 11 días después de la vacunación.

En 1991, los Centros para el Control y la Prevención de Enfermedades, en Atlanta, Georgia, creó un proyecto para vigilar los efectos adversos de todo tipo de vacunas (Vaccine Safety Datalink). Sobre la base de los datos recolectados por dicho proyecto, que se llevó a cabo en una cohorte obtenida de cuatro grandes centros integrales de salud (HMO) en Estados Unidos, un grupo de investigadores estudió la relación entre las vacunas DTP y MMR y una primera convulsión, así como sus efectos en niños propensos a sufrir convulsiones. El estudio, que abarcó 679942 niños menores de 7 años, se efectuó mediante la revisión de fichas clínicas y de datos automatizados. En total se estudió el efecto de 340386 dosis de vacuna DTP y de 137457 dosis de vacuna MMR, en comparación con el efecto de no haber recibido vacunaciones recientes.

Los resultados indicaron que la vacuna DTP se asoció con un mayor riesgo de sufrir convulsiones febriles solamente el día de la vacunación (riesgo relativo (RR) ajustado, 5,70; IC95\% de 1,98 a 16,42). La vacuna MMR se asoció con un riesgo aumentado de convulsiones febriles 8 a 14 días después de la vacunación (RR, 2,83; IC95\% de 1,44 a 5,55). Ninguna de las dos vacunas mostró una asociación con convulsiones que no fueran febriles. El número de convulsiones febriles que sufrió cada niño como consecuencia de la administración de las vacunas DTP y MMR se estimó en 6 a 9 y en 25 a 34, respec- tivamente. Al compararse los niños vacunados que sufrieron convulsiones febriles con otros niños que también las sufrieron sin haber recibido ninguna vacuna, se encontró que los primeros no estaban en mayor riesgo que los segundos de sufrir convulsiones o discapacidades del desarrollo neurológico en fecha posterior.

En resumen, se ha documentado un riesgo aumentado de sufrir convulsiones febriles en niños menores de 7 años después de ser vacunados con las vacunas DTP y MMR, pero este riesgo no parece asociarse con ninguna consecuencia adversa a largo plazo. (Barlow WE, Davis RL, Glasser JW, Rhodes $\mathrm{PH}$, Thompson RS, Mullooly JP, et al. The risk of seizures after receipt of whole-cell pertussis or measles, mumps, and rubella vaccine. $N$ Engl J Med 2001345(9):656-661.)

\section{No es necesaria la supresión vírica completa para obtener beneficios perdurables con los regímenes antirretrovíricos de gran actividad (HAART)}

El tratamiento antirretrovírico de gran actividad (highly active antiretroviral therapy, HAART) no siempre suprime la presencia del virus de la inmunodeficiencia humana (VIH) en el organismo. No obstante, este régimen puede aportar beneficios clínicos perdurables, según demuestran dos artículos recientes. Uno de ellos examinó la prevalencia y el valor predictivo de la viremia intermitente durante un régimen terapéutico combinado. El otro evaluó la resistencia del VIH-1 a la HAART en 18 niños y adultos con cargas víricas de $<50$ copias de ARN vírico por mililitro de plasma. Los regímenes a base de HAART variaron de un paciente a otro, pero siempre contenían un inhibidor de proteasas.

El primer estudio, efectuado en la Universidad de California en San Diego, se realizó en 584 pacientes positivos a VIH que recibieron una combinación de indinavir y dos inhibidores de nucleósidos de la transcriptasa inversa. Los resultados demostraron que la viremia intermitente se presentaba con bastante frecuencia y que se asociaba con mayores niveles de replicación vírica, pero que no parecía asociarse con el fracaso del tratamiento antirretrovírico.

En el segundo estudio, que se realizó en la Universidad Johns Hopkins en Baltimore, Maryland, se 
descubrieron niveles muy bajos de viremia que parecían estar presentes desde antes de la iniciación del HAART, y no como resultados de mutaciones producidas por este régimen terapéutico. La presencia de esos bajos niveles de viremia no mostró ninguna asociación con el fracaso del tratamiento.

Los resultados de estas investigaciones ponen en tela de juicio la creencia de que hace falta conseguir una supresión vírica completa para poder obtener beneficios clínicos perdurables con el uso de los antirretrovíricos. Se recomienda, por lo tanto, no interpretar con demasiada rigidez las pautas clínicas actuales. Aunque en teoría una mínima presencia de virus en presencia de un tratamiento antirretrovírico debe llevar a la aparición de resistencia medicamentosa y a una replicación vírica de rebote, eso no parece estar ocurriendo en la práctica. Quizá se deba a que las mismas mutaciones que le permiten al virus escapar de los efectos letales del medicamento podrían estar impidiendo su replicación. También es posible que una pequeña cantidad de virus sea beneficiosa en tanto que limita y mejora la respuesta inmunitaria contra el VIH. (Havlir DV, Bassett R, Levitan D, Gilbert P, Tebas P, Collier AC, et al. Prevalence and predictive value of intermittent viremia with combination HIV therapy JAMA 2001;286:171-179 and Hermankova M, Ray SC, Ruff C, Powell-Davis M, Ingersoll R, Dáquila RT, et al. HIV-1 drug resistance profiles in children and adults with viral load of $<50$ copies/mL receiving combination therapy. JAMA 2001;286:196-207.)

\section{Se elabora la primera vacuna sintética contra la malaria}

Según ha informado un grupo de investigadores, ya se cuenta con la primera vacuna sintética contra la malaria. La vacuna, que posee una proteína propia de la superficie de Plasmodium falciparum, es la primera en provocar una respuesta inmunitaria celular y humoral. Hasta ahora, ninguna vacuna ha logrado estimular con igual eficacia la respuesta mediada por linfocitos $\mathrm{T}$ y $\mathrm{B}$.

Los investigadores, de la Universidad de Lausanne en Suiza vacunaron a 16 sujetos sanos tres veces durante un período de 6 meses. Al año no se había observado ninguna reacción adversa a la vacuna. La primera inmunización estimuló una abundante proliferación de leucocitos, la cual aumentó después de la segunda inmunización y permaneció estable por espacio de dos meses. Después de la primera dosis se observó la producción de interferón gamma en 3 de los 16 sujetos voluntarios, y después de la segunda dicha producción fue observada en 13 de los 15 voluntarios vacunados. Este hecho re- viste importancia porque la producción de interferón gamma es indispensable para la eliminación del parásito del organismo.

Con las vacunas elaboradas anteriormente a base de técnicas genéticas recombinantes, P. falciparum ha mostrado la capacidad para mutar y de ese modo hacerse resistente al efecto de la vacuna. El uso de una vacuna a base de péptidos sintéticos tiene la ventaja de que es más fácil lograr que tenga eficacia contra varias cepas del microorganismo patógeno, puesto que se pueden hacer muchas variaciones en distintos puntos de la secuencia peptídica de la vacuna. Además, los péptidos sintéticos son menos peligrosos que los que se logran mediante técnicas genéticas recombinantes, lo cual permite que las vacunas sintéticas lleguen a estudiarse mediante ensayos clínicos más pronto. El inicio de los ensayos de fase II con esta nueva vacuna sintética está programado para enero de 2002. (Lopez JA, Weilenman C, Audran R, Roggero MA, Bonelo A, Tiercy JM, et al. A synthetic malaria vaccine elicits a potent CD8(+) and CD4(+) T lymphocyte immune response in humans. Implications for vaccination strategies. Eur J Immunol 2001;31:1989-1998.)

\section{La presencia de varios tipos de virus del papiloma humano en mujeres con displasia cervicouterina: ¿qué significa?}

Diversos tipos de virus del papiloma humano (VPH) se encuentran a menudo en el tracto genital inferior de mujeres con displasia cervicouterina, según un informe que se publicó en el número de agosto de Journal of American Virology. Si bien es cierto que la asociación entre el VPH 16 y la displasia cervicouerina se ha documentado desde hace mucho tiempo, la importancia que pueda tener la presencia simultánea de otros tipos de VPH no se ha estudiado a fondo debido a la falta de métodos capaces de identificar a las distintas cepas en épocas pasadas.

En un estudio reciente, un grupo de investigadores de la Universidad de Indiana en Indiannapolis usó un ensayo de inmunoadsorción inversa a base de la reacción en cadena de la polimerasa para detectar y cuantificar parcialmente 26 tipos de VPH genital. Fueron estudiadas 34 mujeres con displasia cervicouterina, 21 mujeres con células escamosas atípicas de dudosa implicación (CEADI) y 55 testigos con resultados citológicos normales.

Se detectó ADN de VPH en el aparato genital inferior de $94,1 \%, 71,4 \%$ y $54,5 \%$ de las mujeres con displasia, CEADI y resultados citológicos normales, respectivamente. ADN de VPH 16 se detectó en $34,3 \%$ de las mujeres con displasia cervicouterina y 
en $9,1 \%$ de las mujeres sin displasia. En promedio, más de tres tipos de VPH fueron detectados en mujeres con displasia, en comparación con solamente un tipo en mujeres con resultados citológicos normales.

La robustez de la prueba a base de la reacción en cadena de la polimerasa ha permitido por primera vez identificar muchos tipos de VPH en distintas cantidades en un mismo espécimen cervical. De esta manera se ha logrado entender con mucha mayor precisión que antes varios aspectos del fenómeno de la presencia simultánea de tipos diversos de VPH.

Aunque aún se desconoce la importancia de que una mujer tenga a un mismo tiempo infección cervicouterina por varios tipos peligrosos de $\mathrm{VPH}$, este estudio y otros que han obtenido resultados similares apuntan hacia un efecto nocivo, que aumenta el riesgo de que la mujer infectada llegue a tener una displasia cervical. (Fife KH, Cramer HM, Schroeder JM, Brown DR. Detection of multiple human papillomavirus types in the lower genital tract correlates with cervical dysplasia. J Med Virol 2001 Aug; 64(4):550-559.)

\section{Polimorfismo genético de Plasmodium falciparum dificulta la elaboración de una vacuna}

Un estudio acaba de revelar que Plasmodium falciparum muestra más variabilidad genética de lo que se pensaba anteriormente, lo cual implica que es necesario idear medidas de control más complejas contra el parásito. Investigadores de la Universidad de Carolina del Sur en Columbia y de la Universidad de Roma "La Sapienza" estudiaron la secuencia de ARN de P. falciparum en 23 posiciones diferentes en el genoma.

Encontraron una amplia variación en la secuencia de $\mathrm{ADN}$, particularmente en el África, donde se originó esta especie. El genoma de P. falciparum tiene, al parecer, una diferencia en cada 1000 letras genómicas, lo cual se asemeja a la variación observada en seres humanos. Las implicaciones en términos del tratamiento y la elaboración de una vacuna contra la malaria son muy grandes.

La malaria cobra alrededor de un millón de vidas en el África cada año, así como en el Asia y América Latina. En vista de que el parásito ha empezado a mostrar resistencia contra los medicamentos usados en la actualidad, la comunidad científica ha cifrado sus esperanzas en la elaboración de una vacuna contra la enfermedad. Pero la amplia variabilidad genómica de $P$. falciparum dificulta la elaboración de una vacuna, ya que se torna necesario hacer que esta se dirija a distintos blancos o encontrar combinaciones adecuadas de medicamentos para poder hacer frente al problema.

También es necesario prestar atención a las diferencias que muestra el genoma de P. falciparum en distintos lugares. Es posible que en el continente americano, donde la enfermedad se diseminó como resultado de la práctica de la esclavitud, la variación del genoma sea menor. La implicación es que distintos regímenes terapéuticos podrían ser necesarios en diferentes partes del mundo.

Los métodos terapéuticos que se dirijan específicamente contra ciertos procesos metabólicos de Plasmodium son los más promisorios. La eficacia del régimen terapéutico dependerá, entonces, de la variabilidad genética que muestre la región de $P$. falciparum elegida como blanco. (Hughes AL, Verra F. Very large long-term effective population size in the virulent human malaria parasite Plasmodium falciparum. Proc $R$ Soc Lond B Biol Sci 2001 Sep 7;268 (1478):1855-1860.)

\section{Nueva mirada a los dispositivos intrauterinos de cobre}

Debido a la sospecha, respaldada por los resultados de artículos que se realizaron hace algunos años, de que los dispositivos intrauterinos (DIU) de cobre podían aumentar el riesgo de infertilidad tubárica en mujeres nuligrávidas, este método anticonceptivo de gran eficacia ha quedado prácticamente en desuso. En semanas recientes, una investigación procedente de Family Health International y del Instituto Mexicano de Perinatología ha generado datos que podrían cambiar radicalmente esta situación.

Se realizó un estudio de casos y testigos en 1895 mujeres reunidas entre 1997 y 1999. De esas mujeres, 358 tenían infertilidad primaria debido a la oclusión de la trompas de Falopio documentada por salpingografía. De las mujeres restantes, que fueron las testigos, 953 tenían infertilidad primaria sin oclusión de las trompas y 584 eran primigrávidas. De todas las mujeres se obtuvo información sobre su uso previo de anticonceptivos, entre ellos los DIU, sus relaciones sexuales anteriores y sus antecedentes de infecciones genitales. A cada mujer se le hizo una prueba de sangre para la detección de anticuerpos contra Chlamydia trachomatis. Se aplicaron análisis estratificados y regresión logística para evaluar la asociación entre el uso previo de un DIU de cobre y la oclusión de las trompas.

En los análisis de los datos obtenidos de las mujeres con oclusión tubárica y las testigos infértiles, no se halló ninguna asociación entre el uso 
previo de un DIU de cobre y la oclusión tubárica (razón de posibilidades [odds]: 1,0; IC95\%: 0,6 a $1,7)$. Cuando el mismo análisis se efectuó con las primigrávidas que sirvieron de testigos, la razón de posibilidades [odds] correspondiente fue de 0,9 (IC95\%: 0,5 a 1,6), lo cual indica que no hay asociación entre el uso previo de un DIU de cobre y la infertilidad por oclusión tubárica en nuligrávidas. Tampoco se observó ninguna asociación entre la duración del DIU, el motivo que llevó a la eliminación del DIU, o la presencia o ausencia de problemas ginecológicos.

Por otra parte, sí se detectó una relación entre la infertilidad por oclusión tubárica en nuligrávidas y la presencia de anticuerpos contra $C$. trachomatis en la sangre. Según estos resultados, no parece haber motivo para temer que el DIU de cobre cause infertilidad, pero sí es necesario tomar medidas para detectar y tratar la infección por C. trachomatis. (Hubacher D, Lara-Ricalde R, Taylor DJ, Guerra-Infante F, Guzmán-Rodríguez R. Use of copper intrauterine devices and the risk of tubal infertility among nulligravid women. N Engl J Med 2001;345:561-567.)

\section{Reaparición del virus del Nilo Occidental}

La aparición del virus del Nilo Occidental (West Nile: WN) en el hemisferio occidental en el verano de 1999 representó la introducción por primera vez en la historia reciente de un flavivirus del Viejo Mundo en el Nuevo Mundo. Algo similar había ocurrido ya con otros flavivirus, como el virus del dengue, que se ha dispersado desde Asia a todas las regiones tropicales, o el virus de la encefalitis japonesa (JE), que se ha instalado en las costas del norte de Australia, y es de esperar que, debido al aumento del comercio y de los viajes por todo el mundo, se produzcan nuevas incursiones de flavivirus en zonas donde antes no existían. Este artículo abre un número de la revista Emerging Infectious Diseases dedicado especialmente al virus WN.

Este virus de la familia Flaviviridae (género Flavivirus) fue aislado por primera vez en 1937 en el distrito ugandés del Nilo Occidental (de ahí su nombre). El virus WN posee un genoma formado por una única hebra de ARN positivo con 11000 a 12000 nucleótidos que contiene una región no codificadora (NC) en cada extremo y codifica 10 proteínas: 3 estructurales (C, M y E) y 7 no estructurales (NS1, NS2a, NS2b, NS3, NS4a, NS4b y NS). La proteína $\mathrm{M}$ es sintetizada como una proteína precursora (prM) cuya escisión por una proteasa celular (furina) da lugar a la formación de la proteína definitiva. La proteína más importante desde el punto de vista inmunológico es la glicoproteína $\mathrm{E}$, una hemaglutinina mediadora de la unión del virus a las cé- lulas huésped, responsable de la generación de la mayoría de los anticuerpos neutralizantes. El virus WN forma parte del serocomplejo del virus JE, en el que se incluyen varios virus que también producen encefalitis en humanos: el virus JE, el virus de la encefalitis de San Luis (SLE), el virus de la encefalitis del valle de Murray y el virus Kunjin (un subtipo del virus $\mathrm{WN}$ ). Otros miembros de este serocomplejo son los virus Cacipacore, Koutango, Alfuy y Yaoundé. Todos los flavivirus están estrechamente relacionados desde el punto de vista antigénico, hecho responsable de las frecuentes reacciones serológicas cruzadas. Los miembros del serocomplejo JE están todavía más relacionados y a menudo se necesitan pruebas especiales, como los ensayos de neutralización, para identificar el virus infectante.

Desde que se aisló el virus WN por primera vez, los brotes humanos han sido infrecuentes, destacando entre ellos los de Israel (1951-1954 y 1957) y Sudáfrica (1974). Sin embargo, desde mediados de la década de los noventa se han registrado tres tendencias epidemiológicas inquietantes: 1) el aumento de la frecuencia de brotes humanos y equinos $(\mathrm{Ru}-$ mania, 1996; Marruecos, 1996; Túnez, 1997; Italia, 1998; Rusia, Estados Unidos e Israel, 1999, e Israel, Francia y Estados Unidos, 2000); 2) el aumento de los casos de enfermedad grave en humanos, y 3) las elevadas tasas de mortalidad en las aves coincidentes con los brotes humanos de Israel y Estados Unidos.

El virus WN puede agruparse genéticamente en dos linajes (1WN y $2 \mathrm{WN}$ ), de los cuales solo el primero se asocia con encefalitis en humanos. Se han aislado virus de este linaje en África, India, Europa, Asia y Norteamérica. Además, el virus Kunjin, aparentemente un subtipo del linaje $1 \mathrm{WN}$, circula en Australia junto con el virus de la encefalitis del valle de Murray. Los virus del linaje $2 \mathrm{WN}$ se mantienen en África en focos enzoóticos y no se han asociado con la encefalitis humana. Entre los virus del linaje $1 \mathrm{WN}$, los que recientemente han causado brotes humanos y equinos en Europa y Asia han estado relacionados más estrechamente con el virus WN aislado por primera vez en Rumania en 1996 (ROM96), y posteriormente en Kenia en 1998. El virus responsable del brote de 1999 en Estados Unidos (NY99) es genéticamente diferente de los virus similares al ROM96 y su pariente más cercano es un virus que ha circulado en Israel entre 1997 y 2000 (Isr98). Tan solo en los Estados Unidos e Israel se han descrito casos de enfermedad y muerte en humanos y animales ocasionados por esta variante Isr98/NY99 del virus WN. El genotipo del virus NY99 se ha mantenido estable en los Estados Unidos, con muy pocos cambios genómicos entre los brotes de 1999 y 2000. El brote humano y aviario del año 2000 en Israel fue causado por la cocirculación 
de las variantes ROM96 e Isr98, fenómeno que no es nuevo con los flavivirus. Se han descrito brotes mixtos similares con el virus del dengue. La estrecha relación genética entre los virus aislados en Israel y Nueva York indican que el virus fue importado del Mediano Oriente a Norteamérica, pero sigue sin conocerse el medio por el que tuvo lugar su introducción (aves, mosquitos, humanos u otros huéspedes vertebrados). Una característica llamativa de la epidemia humana inicial que tuvo lugar en la ciudad de Nueva York en 1999 fue la alta mortalidad de las aves, y en particular del cuervo americano (Corvus brachyrhynchos) y otros córvidos, en la epizootia acompañante.

Este hecho llevó al establecimiento de un sistema de vigilancia de la mortalidad de las aves para seguir la diseminación del virus en los Estados Unidos. Los resultados obtenidos mostraron que la actividad del virus se había extendido a 12 estados en el año 2000, desde la frontera con Canadá hasta Carolina del Norte, a $900 \mathrm{~km}$ de distancia. También se observó una marcada diseminación del virus desde la ciudad de Nueva York hacia el norte al final de la primavera y principio del verano, y hacia el sur al final del verano y durante el otoño, coincidente con las migraciones de las aves. Asimismo, este sistema de vigilancia ha permitido detectar la infección por virus $\mathrm{WN}$ en 76 especies de aves. Pese a esta notable expansión geográfica del virus demostrada por el sistema de vigilancia de la mortalidad de las aves, los casos humanos han seguido estando confinados a la ciudad de Nueva York y a los condados limítrofes de Nueva Jersey y Connecticut.

Además de una elevada mortalidad de los pacientes con síntomas neurológicos, los brotes recientes de los Estados Unidos, Israel, Rumania y Rusia se han asociado con otras características clínicas que difieren de las observadas en brotes anteriores, tales como la profunda debilidad motora y la escasa frecuencia de las erupciones cutáneas y linfadenopatías. Las encuestas serológicas realizadas durante los brotes de Rumania (1996) y Estados Unidos (1999 y 2000) han indicado que solo aparece enfermedad neurológica grave en menos del $1 \%$ de las personas infectadas y enfermedad febril sistémica en cerca del $20 \%$. En los Estados Unidos, ambos brotes alcanzaron su máxima intensidad en los humanos en agosto, y en los caballos en septiembre. En el brote del año 2000 se identificaron en cinco estados 14 especies de mosquitos infectados. Como los mosquitos del género Culex son los principales vectores mantenedores del virus en el Viejo Mundo, no es de extrañar que las especies $C x$. pipiens y $C x$. restuans, frecuentes vectores ornitofílicos mantenedores del virus SLE en el nordeste de Estados Unidos, fueran también las especies infectadas con mayor frecuencia en el año 2000. Sin embargo, todavía no se sabe cuáles son las especies más importantes en la transmisión a los humanos ni a los caballos.

La experiencia existente con el virus $W N$ en el Viejo Mundo y con el virus SLE en América permite pensar que el virus WN puede alcanzar una amplia distribución geográfica en el continente americano y llegar a tener una amplia variedad de mosquitos vectores y de especies aviarias huéspedes.

Para prevenir la infección humana por el virus WN se ha puesto en marcha en los Estados Unidos un extenso programa de control de las larvas de mosquitos y de información a la población para tra tar de reducir la exposición a las picaduras de mosquitos. Sin embargo, todavía es necesario estudiar mejor la eficacia y la relación costo-efectividad de estas medidas preventivas y de la aplicación de pesticidas para controlar a los mosquitos adultos. Dado el carácter parcial de los conocimientos actuales sobre la ecología del virus WN, su impacto sanitario en el continente americano y la eficacia de las medidas de control puestas en marcha, es de esperar que siga representando un importante problema de salud pública en el próximo decenio. (Petersen LR, Roehrig JT. West Nile virus: a reemerging global pathogen. Emerg Infect Dis 2001;7:611-614)

\section{Factores de riesgo de infección por el virus de la hepatitis $C$ en jóvenes de la calle}

El papel predominante de las transfusiones de sangre y del consumo de drogas inyectadas en la transmisión de la infección por el virus de la hepatitis C (VHC) ha sido confirmado por varios estudios en todo el mundo. En Canadá, la principal vía de transmisión es el consumo de drogas inyectadas. La tasa de transmisión por vía sexual es baja y la transmisión en el seno de la familia es rara. También se ha descrito la transmisión en otras situaciones que implican la exposición a la sangre, como el tatuaje, la perforación (piercing) de los pabellones auriculares y otras zonas del cuerpo o el hecho de compartir el instrumental utilizado para el consumo de drogas inyectadas, pero se desconoce su importancia relativa.

En 1995, los autores de este estudio iniciaron una investigación sobre la prevalencia de las hepatitis B y $\mathrm{C}$ en jóvenes de la calle de la ciudad de Montreal $\mathrm{y}$ los factores de riesgo asociados con estas infecciones. En el presente informe se describen los resultados obtenidos con respecto a la infección por VHC. Los referidos a la infección por el virus de la hepatitis B (VHB) han sido motivo de otra publicación.

El estudio se realizó entre diciembre de 1995 y septiembre de 1996. Los participantes fueron jóvenes de la calle de edades comprendidas entre los 14 y 25 años, reclutados a partir de un estudio de co- 
hortes en curso (el Montreal Street Youth Cohort Study). Los jóvenes "de la calle" se definieron como aquellos que durante el año anterior se habían encontrado sin un sitio para dormir en más de una ocasión o habían acudido habitualmente a los servicios de la ciudad para jóvenes de la calle. Todos los participantes fueron sometidos a un cuestionario cara a cara de 15 minutos de duración para obtener información sobre sus características demográficas y los factores de riesgo de infección por VHB y VHC. Tras la entrevista se obtuvo una muestra de sangre para la detección de anticuerpos frente al VHB y al VHC. Para detectar los anticuerpos antiVHC, en los primeros 329 casos se utilizó un inmunoensayo enzimático (EIA) comercial y en los 108 casos restantes otro EIA comercial de un laboratorio distinto, cuyas características son similares (sensibilidad del 98,6 y 99,6\% y especificidad del 99,5 y $99,8 \%$, respectivamente). Todas las muestras positivas fueron confirmadas mediante una prueba de electroinmunotransferencia recombinante (RIBA) de tercera generación. Para identificar los factores asociados a la infección por VHC se realizó un análisis de regresión logística multivariada en el que se incluyeron las variables asociadas $(P<0,1)$ a la infección en el análisis univariado.

Los participantes tenían una media de 19,5 años, $303(69,3 \%)$ eran varones, 247 (56,5\%) tenían al menos un tatuaje, $342(78,3 \%)$ tenían perforaciones del pabellón auricular o de otras zonas del cuerpo, $200(45,8 \%)$ se habían inyectado drogas, 232 (53,1\%) habían consumido cocaína en forma de crack, 21 $(4,8 \%)$ habían recibido sangre o productos sanguíneos por indicación médica y 34 (7,8\%) habían recibido inyecciones de medicamentos o vacunaciones fuera de Canadá.

De las 437 muestras de sangre analizadas, 55 contenían anticuerpos anti-VHC, lo cual representa una prevalencia del 12,6\% (intervalo de confianza del 95\%: 9,7 a 15,9\%). La prevalencia fue similar en ambos sexos: $10,4 \%$ en el femenino y $13,5 \%$ en el masculino. Las variables asociadas con la infección de forma estadísticamente significativa en el análisis univariado fueron la edad, el tatuaje y el número de tatuajes, el número de perforaciones (piercings), el consumo de drogas inyectadas, el consumo de crack, la prostitución, el haber practicado sexo anal activo o pasivo, el haber sufrido una o más infecciones de transmisión sexual y el haber tenido más de 10 parejas del sexo opuesto, parejas del mismo sexo, parejas que consumían drogas inyectadas, parejas infectadas por el virus de la inmunodeficiencia humana o parejas con antecedentes de hepatitis no especificada. Entre los factores no asociados con la infección por VHC se encontraban el sexo, el haber recibido transfusiones de sangre o sus derivados, o inyecciones o vacunaciones fuera de Canadá, el haber utilizado cepillos de dientes o cuchillas de afeitar de otros y el haber vivido con alguien que tuviera antecedentes de hepatitis no especificada, pero que no fuera su pareja sexual. Los factores que siguieron estando asociados de forma significativa con la infección en el análisis de regresión logística multivariada fueron el consumo de drogas inyectadas, la edad superior a 18 años y el consumo de crack. Las correspondientes razones de probabilidades (odds) y sus intervalos de confianza fueron: 28,4 $(6,6$ a 121,4$), 3,3(1,6$ a 7,0$)$ y $2,3(1,0$ a 5,3$)$. El tener más de un tatuaje también se asoció de forma casi significativa: $1,8(0,9$ a 3,6).

La prevalencia registrada en este estudio $(12,6 \%)$ fue muy inferior a la estimada en la población general de Canadá $(0,8 \%)$ y a la detectada en otros estudios de poblaciones similares de jóvenes de la calle en Ottawa, Canadá (4\%), Goiania, Brasil (1\% y $3 \%$ ), y Oregón, Estados Unidos (5\%). Esta diferencia podría explicarse por la mayor prevalencia del consumo de drogas inyectadas entre los jóvenes de la calle de Montreal (46\%), en comparación con los de Ottawa (17\%) y Oregón (37\%). En este estudio sobre las hepatitis B y C hubo tres factores que se asociaron con ambas infecciones (la edad, el consumo de drogas inyectadas y los tatuajes). Otros dos solo se asociaron con la infección por VHB (la actividad sexual y las perforaciones) y uno con la infección por VHC (el consumo de crack).

Entre las limitaciones de este estudio destacan el desconocimiento sobre la posibilidad de generalizar sus resultados a otros jóvenes de la calle y el hecho de que la mayoría de los individuos fueran participantes en un estudio de cohortes, por lo que podrían ser menos desorganizados $\mathrm{y}$, por consiguiente, menos vulnerables a la adquisición de la infección por VHC en comparación con otros jóvenes de la calle, con lo que se estaría subestimando la verdadera prevalencia de la infección. Por otro lado, como los participantes fueron remunerados, aquellos que se encontraran en situación más precaria podrían estar sobrerrepresentados y esto podría haber producido una sobreestimación de la prevalencia. (Roy E, Haley N, Leclerc P, Boivin J-F, Cédras L, Vincelette J. Risk factors for hepatitis C virus infection among street youths. CMAJ 2001; 165:557-560)

\section{Variante peligrosa del virus del papiloma humano tipo 16 y el riesgo de cáncer cervicouterino en mujeres mexicanas}

Las mujeres mexicanas tienen una incidencia excepcionalmente elevada de cáncer cervicouterino, lo cual podría atribuirse a la presencia en esa población de una forma agresiva del virus del papiloma 
humano (VPH) tipo 16, conocida por "variante asiático-americana" (AA). El Instituto Nacional del Cáncer de los Estados Unidos de América publicó hace poco un estudio realizado por investigadores mexicanos donde se exploró la relación entre la presencia de este virus y la de cáncer de cuello uterino. El estudio fue efectuado mediante la recolección de muestras cervicales de 181 mujeres con cáncer cervicouterino y de 181 testigos sanas apareadas con las primeras en edad. Las muestras se sometieron a pruebas para la detección de VPH y de variantes europeas o asiático-americanas.

Se detectó VPH tipo 16 en 50\% de las mujeres con cáncer y $11 \%$ de las mujeres sanas que sirvieron de testigos, y en todas menos una de las muestras positivas a VPH tipo 16 se detectó la variante europea o la asiático-americana. Las probabilidades de encontrar estas variantes fueron mucho más altas en las pacientes con cáncer que en las testigos, pero en el caso de las variantes asiático-americanas las probabilidades fueron 27 veces más altas que en mujeres cuyas muestras fueron negativas a estas variantes. En cambio, las variantes europeas fueron solamente 2,7 veces más frecuentes en las mujeres con cáncer que en las testigos.

De las mujeres enfermas de cáncer, las que fueron positivas a VPH de la variante asiático- americana desarrollaron la enfermedad casi 8 años antes que las mujeres positivas a la variante europea. Esta última variante, por otra parte, solamente se asoció con cánceres de tipo escamoso, mientras que la variante asiático-americana del VPH 16 mostró una asociación con el cáncer escamoso y el adenocarcinoma.

La alta incidencia de cáncer cervicouterino en México podría deberse, en parte, al hecho de que apenas 30\% de las mujeres adultas se someten al Papanicolaou. No obstante, es posible que también contribuya a la incidencia la alta frecuencia de variantes asiático-americanas de VPH 16, que muestran propiedades más oncógenas que las variantes europeas. Se deduce de todos estos datos que a la hora de diseñar una vacuna apropiada contra los VPH para una zona específica, es preciso tener en cuenta no solo los distintos tipos de VPH, sino también la prevalencia de diversas variantes de estos virus. (Berumen J, Ordonez RM, Madrigal de la Campa A, Laboratorio Multidisciplinario de Investigación, Escuela Militar de Graduados de Sanidad y Escuela Médico Militar, Universidad del Ejército y Fuerza Aérea, México D.F. Asian-American variants of human papillomavirus 16 and risk for cervical cancer: a case-control study. J Natl Cancer Inst 2001;93(17):1325-1330.)

Among the more important practical considerations affecting retrospective studies
is that they are ordinarily designed to follow the line of least resistance in obtaining
case and control histories. This means that cases and controls will often be hospi-
tal patients rather than persons in the general population outside hospitals. As
a result, any factor which increases the probability that a diseased individual will
be hospitalized for the disease may mistakenly be found to be associated with the
disease.
[Entre las consideraciones prácticas más importantes que afectan a los estudios
retrospectivos se encuentra el hecho de que por lo regular están diseñados para
seguir el camino más fácil en la obtención de historiales de casos y testigos. Esto
significa que los casos y testigos frecuentemente serán enfermos hospitalizados
en lugar de personas de la población general fuera de los hospitales. Como resul-
tado, cualquier factor que aumente la probabilidad de que un individuo enfermo sea
hospitalizado debido a la enfermedad puede erróneamente parecer que está aso-
ciado con la enfermedad.]
NStatistical Aspects of the Analysis of Data from Retrospective Studies of Disease"
Journal of the National Cancer Institute 1959;22(4)

